\title{
O TRABALHO COM NARRATIVAS: PERSPECTIVA METODOLÓGICA PARA O ENSINO SUPERIOR.
}

Josemile MAU Is

Uniwersidade Fedectal din l'ald

\begin{abstract}
Essas regras näo defrnen am mélodo, thas ben exatumente thin êxodo, una corrila tapridiosa que porece irreonlar, thas coagida apenas pela obrigaça de evilar os lugtare eppealatios, gaxantidos pela jorka e, rm geral, viguados pon

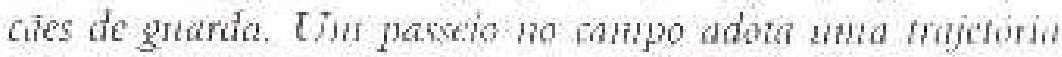
semelhante, inerpernda e recortada... (Michicl Serres)
\end{abstract}

Resumo: Lise trabalibo tradnz a busca da construsgà de

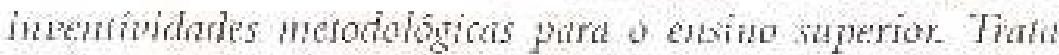
de nom dinensäo do trabaltho docente nito raramente

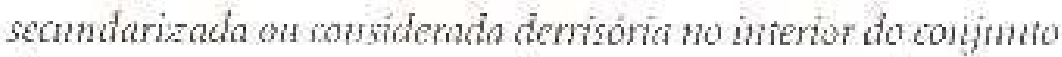

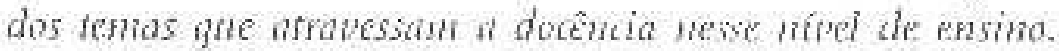
Pura o tratamento de questos metodologicas nesse nód de

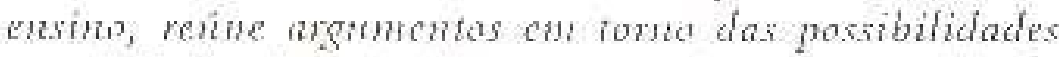
metodologicas do frabaltw com namarisas wo exerício da dokêniza no Ensmo Superior. Opera con nua noçāo de metodoligia ane nos remete sempre a movimentos do pensanento e a ma conjanio de protedinentos a partir tos

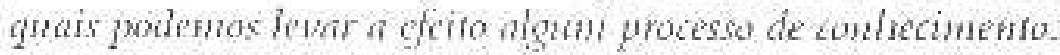
Train-se portanto de perspesilia que nāo pode prescinclir de

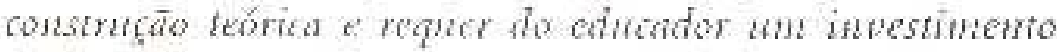

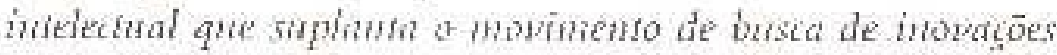
en forno de sen modus opetandi. Por esca fizño, assume

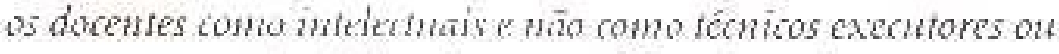
personagens cujo oficio seja aprendido pela mínese.

Formularci neste texto utua discussẩi da construção metodológica no ensirzo superior, deftadendo sua íntima articulaçắo eotn a discussão 1córica exigida para os processos littlo ale produçāo quanto de disscminaçao do conbesirmentos nil ambiência universitária. A partir da perspectiva defendida neste texto, a questāo neetoblolósgica é assumida como discussâo curricular joì dì respeito ao cnvolvmento dos sujeitos 
13: ketinição dos modos como determinados conhecimentos ganham sinn nificados e participam de processos a partir dos quais são construídas pusiçóes $\mathrm{cm}$ relação ao mundo e a si próprios. Ainda nessa perspectiva, (1) acesso a determinados conhecimentos em situações de ensino se dá através de processos de significação que são sempre mediados pela linguagem. ${ }^{1}$ Os docentes são assumidos como sujeitos que operam cm scu trabalho nas tramas da linguagem que não se resume a processos de comunicação oral, ou a textos letrados, mas abarca toda forma de cxpressão que atribui sentido e que, ao fazê-lo, institui, inventa, cria algo. Os currículos são assumidos como relaçōes sociais, como campos de produção e criação de significados. Trata-se portanto de uma perspectiva teórica que enfatiza as propriedades subjetivantes da linguagem.

As narrativas são assumidas como relatos em meio aos quais, através da linguagem, os sujeitos significam a si próprios c a suas práticas e experiências nomeadas, definidas e relatadas. São estórias que contamos tuns aos outros e a nós próprios. (ROSE, 2001, p.151). Trata-se de relatos construídos a partir dos posicionamentos que os sujeitos assumem no interior de uma ordem particular de saberes e discursos. A linguagem é assim vista como instância de expressão e constituição de subjetividades.

Com essa demarcação delinearei, $\mathrm{cm}$ um primeiro momento, a ancoragem teórica dessa proposta e, $\mathrm{cm}$ seguida, alguns indícios de uma composição de trabalho curricular com narrativas no campo da formação docente no ensino superior

\section{Da ancoragem social e teórica da perspectiva proposta para trabalho com narrativas.}

\section{Da ancoragem social}

Do ponto de vista de sua ancoragem social, a perspectiva aqui proposta volta-se para o enfrentamento de algumas contingências hoje

\footnotetext{
A perspectiva teórica da qual este texto é tributário recorre às indicaçōes das chamadas tcorizaçōes pós-críticas, mais especificamente, aos aportes do que tem sido chamado de crítica pós-cstruturalistas que assume a linguagem como operação constitutiva implicada na produção do que as coisas são. Em alguns momentos serão referidos autores que podem não se enquadrar nessa perspectiva entretanto são acionados por trazerem a discussĩo da linguagem como importante elemento para compreensão c análise do fenómeno educativo,
} 
...h « . ulis para a docência no ensino superior. Dentre um conjunto muito 11... .ımplo de injunçöes ressaltarei aqui, duas delas por apresentarem, " "u'u juízo, maiores relações com a perspectiva que aqui alinhavo.

A primeira dessas contingências pode ser identificada no modelo 14. carrcira que vem presidindo o magistério $\mathrm{cm}$ nível superior e que wh a a pesquisa como sua base principal, secundarizando o ensino e a 'venșão. Em seus desdobramentos, essa sobrevalorização da pesquisa whoca em campos separados a opção metodológica envolvida na Iruduçāo do conhecimento, da op̧̧ão metodológica envolvida no frucesso de veiculaçāo de conhecimentos no processo de ensino, como "xistisse um distanciamento substancial entre a compreensão e a prustura face à verdade que está em jogo no processo de produção de wnhecimento e a concepção presente na disseminação do ensino. Como $x$ fossem diaspóricos a postura e o movimento do pensamento que issumidos no processo de pesquisa e a postura e o movimento do pensamento adotados na atividade do ensino.

Essa colocação certamente não quer dirimir as especificidades da metodologia de pesquisa e da metodologia de ensino. Quer antes realçar os liames entre pesquisa e ensino, ressaltando os vínculos entre produção e disseminação do conhecimento no nível superior ;assumindo a pesquisa como instrumento da prática profissional do professor universitário em suas diferentes dimensōes e, mais especificamente, como princípio cognitivo importante para a formação de professores. Mas quer, fundamentalmente, investir na construçāo desses liames a partir de uma perspectiva de construção de conhecimento pela via da pesquisa que enfrente corajosamente (e perigosamente) os questionamentos que as formas canônicas de produçāo de conhecimento vêm sofrendo nestes tempos transicionais.

A segunda dessas inflexōes diz respeito às atuais políticas de graduação e formação docente que vêm enfatizando uma suposta epistemologia da prática onde a construção teórica é desvalorizada ou considerada obsoleta. A partir de uma lógica empiricista, o trabalho formativo passa a ser tonalizado por operaçōes metodológicas $\mathrm{em}$ que a experiência vivida parece prescindir da teorização e da reflexão crítica, a mímese substitui a criação e o treinamento em serviço substitui a construçāo de aportes teóricos por respostas eficazes em tempo real.

Nesse sentido, vale ressaltar que trabalhar com narrativas, na perspectiva aqui assumida, não significa o envolvimento em operaçōes 
catárticas ou $\mathrm{cm}$ cnleios românticos que, cm nemo da primazia do discurso, considerem válidas e puras todas as formas de cxpressĩo, simplesments: purque social, discursiva e intersubjelivamente produzidas. Sob a perspectiva aqui assumida é precise admitir que năo liá natrativas incontestes, inunes à interpretaçăo, ao dissenso.

Comb encontramos na afirnativa de GIROI JX ( 1999, p. 97$)$

Comentrat se na voz näo signifia sinplestente afiruar as historias que or alunos contam, nimi simplesniente glorificor a possibilidade da nammgrio, Essn posigrio en geral se degenera

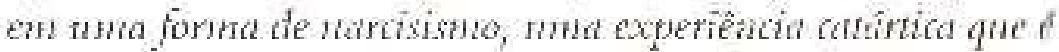

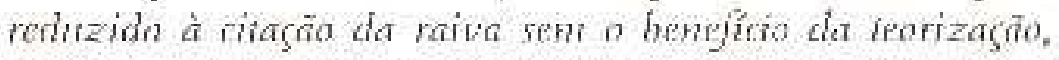
pon ao mesmo tempo conprender stias musas biascas e o que significa trabalihat coletivamente pata thasformar as esiruturas de dominagño responáveris por relagoes sociais expressivas.

Nāo sāo as supostas revelaçoes ou ocultamentos indiciados nas flarrativas que tue interessam. Como instâncias e momentos de geraçăo de significados pelos quais os sujeitos explican a si mesmos is a mondo, interessa-me apreender as condiçoes históricas de sta produçāo, a

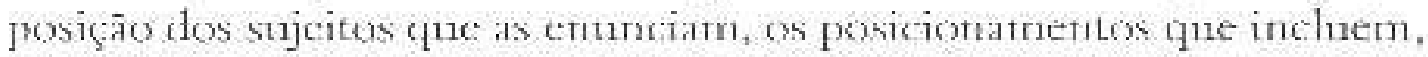
a atribuiço de valores, as catcgorias de pensamento, as difercnciaçócs, saberes e verdades que cartegntm. os significados que inprituem acerca do que é cducaço, do que ć docencia: em suma, sua plasticidate na fabricaçào de certas formas de subjetividade.

() Lrabalko com tarrativas inplica semape o envolvimenco con as estórias que as pessoas contam, com as recriaçóes, c com os significados arribuidos às experiências vividas c narradas. $\Lambda \mathrm{o}$ se aliarcm às rupturas relacionadas a modelos convencionais de invextigaçăo nas ciencias sociais, ntostram cono a subjefindade passa a se constituir em idéa madear e ariouladora dris noras formulaços teórias due realinentan as diversas áreas. (BUENO, 2002, p. 1) Ao mestrio tempo em que dimimetn o hiato entre o movimento de produção de conhecimento co de sua disseminação, posicionam-se contrariantente à loggica de supervalorizaçăo da prática que se vem imprimindo nos cursos de formagion de professores. Sob a perspectiva aqui anunciada, passa-se a comar a vida, as carreiras, os percursos profissionais, as biografias, as autobiografias docentes oin dos firturos docentes como objeto de conhecimento no ensino. 
2. Da ancoragem teórica: alguns sinais de veconhecincnto en termos it. linguagem e subjetividade.

A busca de possibilidades teórico-metodolog cas de prequasa em

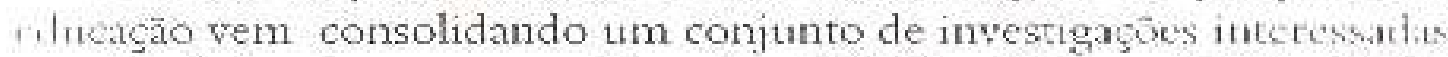
was hiscótias das pessoas Goodson(1992), Nowoa (1988, joxp).

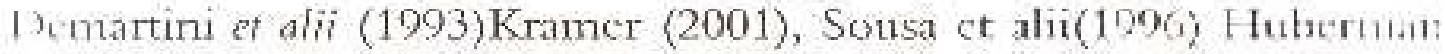
(101/2) Bueno (2002) Mignor \& Cumha (2002) säo aiguns dos zutores ruc, sob diferemes clivagens téricas, vêrn apestando nas modalidales

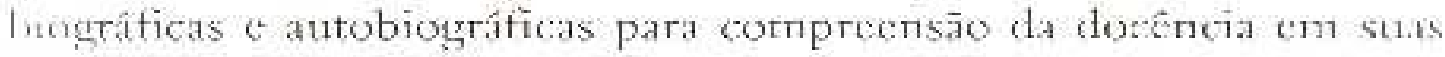
liferentes dimensôcs c para a açâo formativa. Operando em stuts variaçues conn narrativas de remenomąăo oblidas acravés de diferentes relatos, ou com materiais biográficos secundários, corao diáries, cartas, fincografias, documentos, csses trabalhos pōem scmpre cm evidência importatites eletuentos relativos à linguagetn a constituição das subjetividades docentes e na construçấo de trajetórias profissionais e tie formaçăo.

Respoitandos as detrarcaçes Lebricas que esses estudos apresentam C Investindo nas modalidades narrativas como elcmentos que

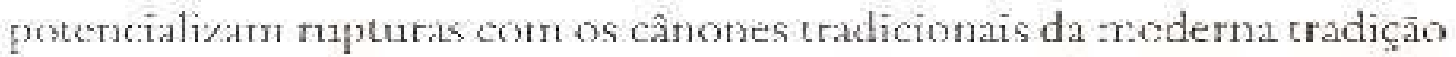
de pesquisa, a possibilidach: metodologica do trabalho com tiarrativas no ensino superior que desenvolverei neste texto, vale-sc de clementos da discussão pós-estruturalista ${ }^{2}$ em termos da questán da frimazia do discurso, como elemento cnvolvido na constituiçāo das subjetividades. E sob os auspicios desta perspectiva teórica que descuvolverei os argumentos em tormo do trabalbo curricular com natralivas, num esforço de articulaça tcórico-metodológica de pescjuisa e cnsino, (cesfihratick as contexóes entre linguagetn e produção de subsecividades, como enucleaşós bísicas para esse emprectidimento.

Essa formulaçāo torna-sc possível a parit dia comprescsāo da linguagem como um sistema de significaçấo em que os significados sĩo

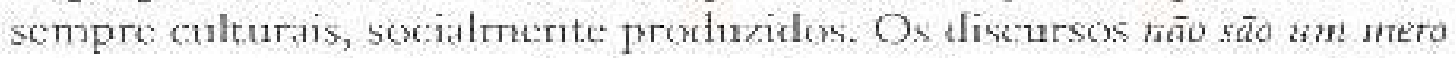
entreanzanenth de coisas e de palavras $[. . .7 \mathrm{am}$ intrincanenio entre un texiro e.

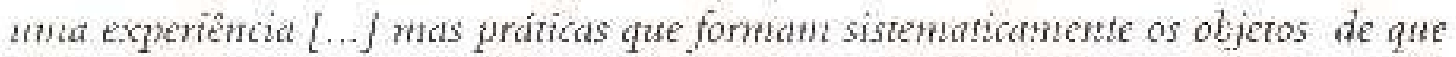
falam.(FOUCAULT, 1995, p. 56).As práticas discutsivas măo sĩo

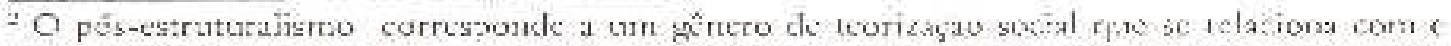
tmanscende a estrucitalismo, centrando sua enfase no processo de signiticeçio sferade pela

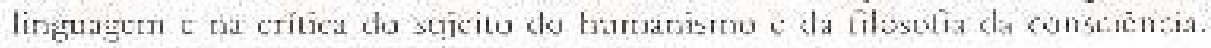

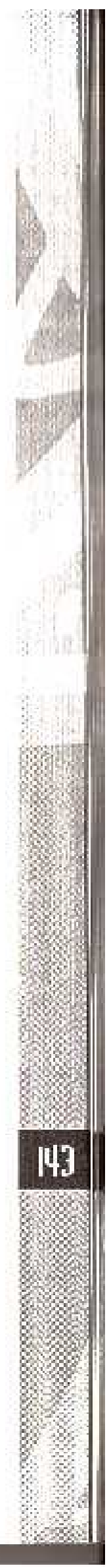


ighalmente operaçoses expressivas por mejo das quais os sujeitos formulan idéias mas un conjonto de regrns anônimas, hisónicas, sempre

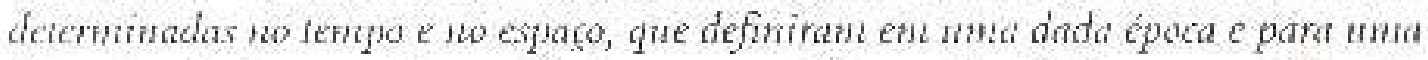

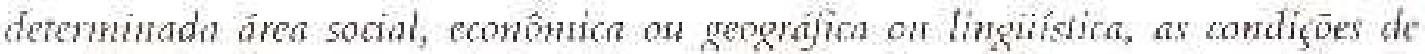

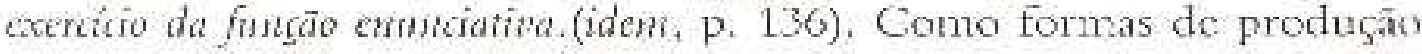
de: discursos sāos recontecidas etn sua corporificaçãu nas instituiçóes, cm padröes de comportamento, em formas pedagógras, em diterentes operaçes enwolvidas no processo de ensmo.

Suh a inspiraça foucaultiana, os discursos sāo materialmente produzidos por arranjos sociais, políticos, teconômuicos específicos; as regras dos discursos governam o que podc ou nâo ser dito; cuem pode fitar som antoridade e quen deve escutar; diferentes regimes c processos de apropriagro do discurso são produzidos e governados por relaçóes de poder. Os textos c discursos são assunidus como constitutivos das subjetividades; interessa ver os modos como constrocm as realidades e posicionam os individuos.

hinda sob essa inspiraço

Renunciaremos, pois, a ver no discurso un ferôneno de expressāo a traduçăo verbal de unia sintese reatizuda em algnm ontro lugar; nule busaremos antes inm cumpo de regularidade para diversis posicós de subjetividade. $O$

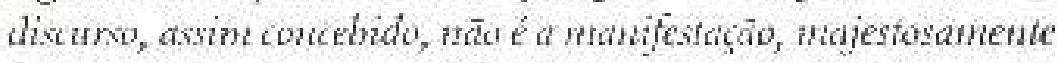
desenvolvida, de nm sujeiro que pensa, gre conthese, eque diz: $\hat{\varepsilon}$, ao contrário, an conjunto ch que podem ser determinadas a disperāo do sujeito e sua descontinuidade em relaçio a si mosno. (FOUCAULT, 1995, p. 61-2)

Privilegion tuo Labalho com narrativas, nāo a busca de seus significados subjacentes, scus envirzancmtos ideoligicos, suas possibilidades redentoras. Assumo a linguagen como agenciamento, precompando-rme, como coloca ROSE (2001, p. 159) wōo con o que da conmunion "quer dizer" on "sjgnifica mas com a que dia faz, que componentes de pensamento ela coloca em conexio, que pinculos da desqualifita, o gite cnpacita os hnthanos a imaginar, a diagramar, a fantaxiar zma detemninada exisêntia, a se retuiten en um sigenciamento.

Desse modo estou preocupada nắo com a irrupçảo de subjetividades no processo de narração de estórias netn com a aţálise da retórica; mas, com o exame dos diferentes agenciamentos de sujeitos 
fututes, on da construçás discursiva do cu atraves de croterias de

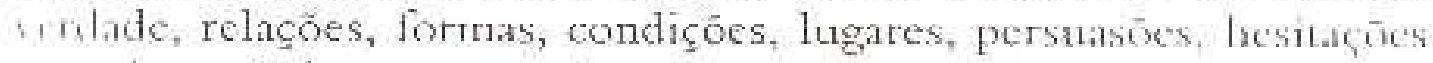
whtrubstanciadas em narrativas.

$O$ cntcndimento da lirguagem, como elefrento quic eutra na - rustituiça das experiencias, das subjetividades e que anda possiluluit

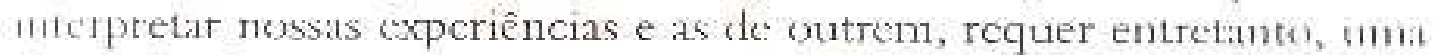
le.terminada compreensão de subjctividade ou como nas palavias d.

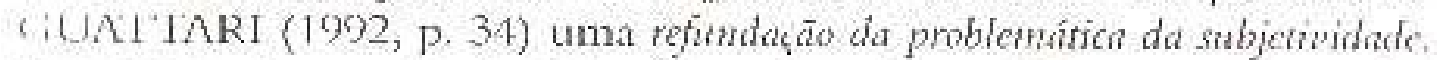
fira esse antor a subjetividade é a conjunto das condigūes que torna possind

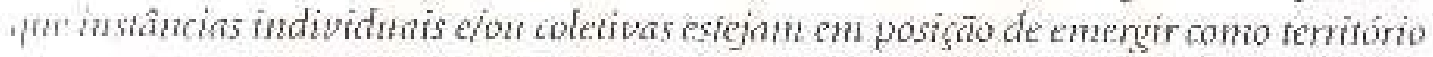

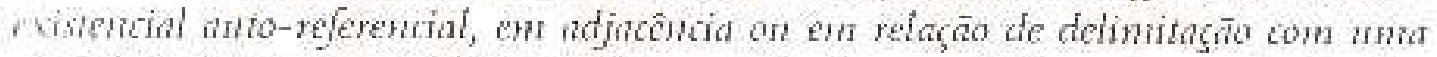
whriade ela neona subjetiva (idem. p. 19). As condiçoses de produçāo das mbjetividades cnwolvem diferentes: substâncias de expressāo lingüisticas

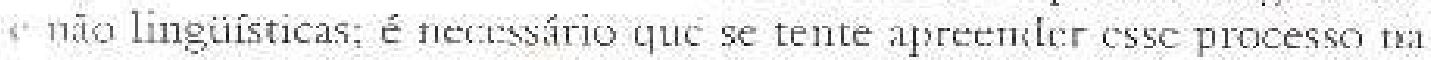
slimensão de sua criatividade processunal.

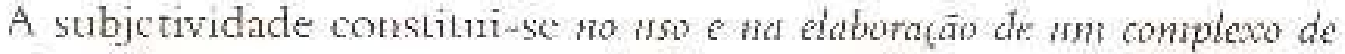

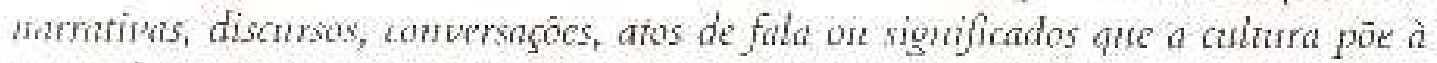
hossa dinwsigna e que manipulanos flar ralidates interacionals que habitanos. (T)OMENECH et aiii, 2001, P. 119).

De omtro modo, posso dizer que; como subjetividades, sonos proshrixidos e nos movimentamos cm meio a inúmetas camadas de discurso, que simultancamente nos erelunsuram e possibilitam recriaços a reapropraços. A prôpria noço de subjetividide procisa ser assumida como processo multifacético, socialmente produzidose oposto à suposiçĩo de sujeito unitírio, autoconstituinte : prediscursivo.

Ao focalizar rua subjetividade através do trabalho com narrativas, nầo estou postulando perspectivas individualizantes. Se atento para a nogān de subjetividade desenvolvida por GUNI"IARI (1996) isso certamcnte não quer dìcr quc todo processo de transformação seja individual, pois que a perspectiva desse autor nấo consiclera a subjetividadc coletiva como resultante de utra somatória de subjetividades sociais. Contrariamente, o processo de singularizaçāo da subjelividade é percebido no efıLtecruzancinto de dimensóes variadas sc.jam clas biológicas, sexuais, sócio-econômicas, tccnológicas, discursivas, de: mídia, curre outras, num confronto com modus de fabricaño globais de subjetividate:

Compreetsder os modos como as subjetividades dos docentes e as subjetividades dos estudantes se cvidenciam e se ocultam nos diferentes 


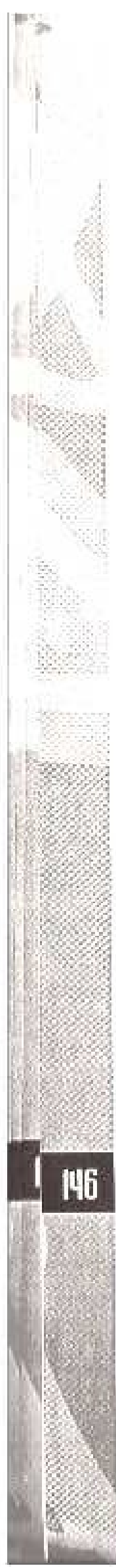

modias narrativos possíveis de serem examinados c intrepretados, abre un diversiticato leque de questōes que pōm em evidência o multírgeno conjunto de deccrminaçöes, de rebeldias e de acomodaçócs que configurams a luta pela afirmacăo dos discursos e das cxistêtucias em determinados contextos sócior-nilturais.

Remeto-me a urn tratamento dapuile que narram os witudantes como

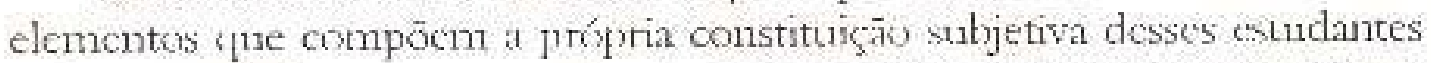
\& săc atravessadas por um conjunto de injunç̧ós discursivas provonicrites

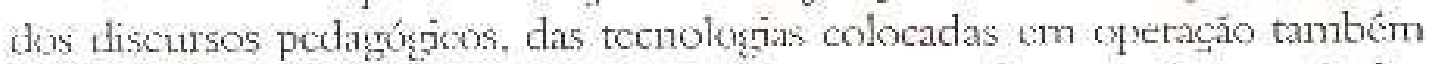
no trabaltwo docente, dos ckinentos de lingnaızen dos próprios currículos conno tais. Todus esses discursos săo atimados por 11 rma vontade de verdade

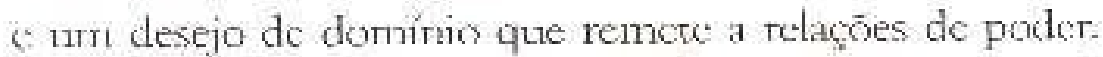

Otraballo com narrativas sob cssa perspectiva nāo e desenvolvido nem no strnticlo de analisar as experiencias dos individuos nom para analisar os conteúutes léxicos do que narram os estunlatutes ou para buscar os sentidos das palavtas que compóem essas narrativas. $\hat{A}$ maneira foncaultiana, é preciso tentar fiear no nivel do discurso (FOUCAULT, 1925 , p. 5) o quc năe signfica, como já coloquci reiteradas veres neste texto, sediar-se cm investimentos loxicos; thas implica, sobremancira, na idcutificasăo dos relacionatrentos que caracterizam as narrativas como práticas discursivas que conscituem aquilo de que om sobre o que talam.

Ao examinar narrativas, devenos jreocupar-nos com a política que institucrn, com o regine de verdade que os discursos que acolhe e far funcionar conno verdadetros compreendem (idem, p, 12); com a economia política da verdade configurada e gue tem como uma de suas caractcrísticas ser produzida te Lansmitida sob o controle de alizuns mratudes aparcllons encre os guais se encontra a universidade. (FOUJCAULI, 1996).

\section{De uma composiçâo do trabalho com narrativas na formaçăo docente}

"O que interessn agora é l.../ Pinsar da formaçăo para a composiçăo, do desenvolvimmo para a combinaçāo, da otganizasio para o agenitumento." (CORAZZA \& SILVA).

Esboçado o solo tcórico e social que mobiliza a construçăo metodológica que vertu expondo, passarei a indicar algurse elementos 
'fre jodem compor urma forma de trabalho com radrativas ne ensino illerior, advertindo, entrecatito, para os fato de que não se colocim em - pialfuer persfectiva fuodelar, tras como nun esforco constructomista Itic nivest: contra as antigas territorialidades fnctodológicas baseidas 11.1 preleçăo-fixaçăo-avalias̆o.

Nessas condicóes, cabc especialmetute lembrar que, conno sujeitus wh ias e rrabaltadores culturais ervolvidos com a formaçäo de whadores e educadoras, os docentes se encontram profundamente 11iplicados tra produçio de natrativas e de subjecividades. Se este é o 1.11:po conditivo com o qual nos defontam cotidianamente, c possivel Ifue sejil também estc o território onde poderäo construir contrafluxos nii sentido da recseritura da prática política e pedagograca no campo chlucacional.

Como ventro argumentando ao longo deste texto, esse tipo de

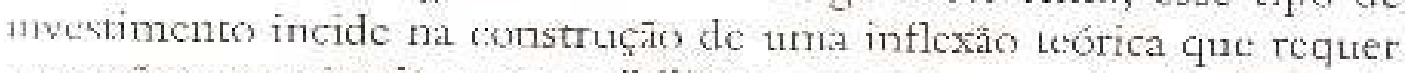
iperaçóes conceituais que possibilitetn novos luğars:s de circulaçâo dt: whido to diferentes posiciomamentos accroa do saber sobs: a pedayosga, whretudo no que diz respeito ì relaçes entre o sujeito e o stiscurso. $A$ desestruturaçio de algutrats sediuru:ntaçôes prescntes nas discursos peclugosicos e, certamente, um processo extrcmamente complexo.

Como aprosenta DIA $(1998, p, 17)$.

Os professues são, inciahmente, dematiarlo sausinvianes para

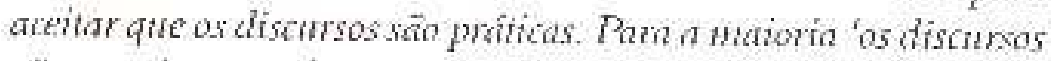
săo conjunios de signos', 'a lingntigem esta theia de signos'... portanio movestá vazia. Dexe modo ten sido cricial para os projesores comprectuter que vivenos fuersos en conjufutos de práticas discursivas que tāo sentido a nossas relagcenes sociais, à estrusma de nossa coidinnuidade; e que tais prátion disursivas eniram, por sia vez, no jogo das relaçoes de poder.

Utra das possibilidades metodologicas para operar com as rudetiniçōes do poder, do sujeito e do discurso na perspectiva acjui whlineada, pode ser desencadenda, ao se trazor para o âmbito do traballuo político-pcdagógrico a açāo narrativa como possibilidade de 1114errogartuc-nos sobrs; as relaçócs historicas, suciais e culturais cnvolvidas nas posiçōos que os sujeitos assumem enquanto efeiton de. tiscursos e errquanco produzidos no interior de discursos. 
Este programa cormpreende o esforço concreto de traballo com múltiplas tomas narrativas a partir das quais os sujeitos conferem sefilido e significado a si próprios, ao mundo c aos outros. Trata-se assim de uma especie de recontextudi lizaçăo da açăo narrativa para o àmbito pedagógico, banida que foi por ser, sob a útica da razāos científica modertıa, cotssidetada ilógica. Essa reabilitação significa cxtcnsivamente - próprio recneontro com a sirbjetividade que como muito apropriadamente coloca MORIN (1996, p. 46) aparece na ciencia clássica

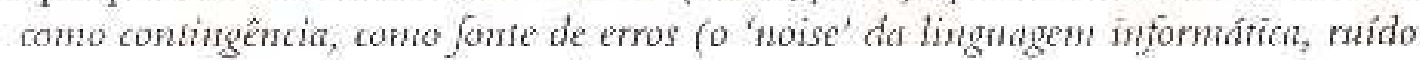
que é absohntanen (e necessário eliminar).

Venho argumentando guc o ato de narrar on aimsla o exatre e interpretaçio de narrativas produzidas, pôm em evidència um conjunto dre poriçoses - cle sujeits - que a linguagen, en sua ativa participaçẩo na produçâo de subjetividades, evidencia, Ativam aincla pela via da tnemória unn conjunto de experiências, representaçocs, descjos, scnsaçócs, crenças, valores c raciocinios construídos pelos sujeitos em seu esforço de significação e de atribuição de sentidos em relaçâa a si mestnos, ao munklo que os citcunscrevem e interpelam e ao outro.

Estc pode ser un importante recurso gnosiolónico e pedangígico que purle etjvolver professores e estudantes na compreensäo ativa dos modos de conformaç̄ono de suas subjetividades, de produção e legitimaçăo de narrativas, bem como deslindar os modos pelos quais práticas discursivas cstruturam nossas vidas de frodos concretos, específicas e incisivos. Podc, anda, ao identificar a natureza constitutiva dessas operaçōes balizar $u m$

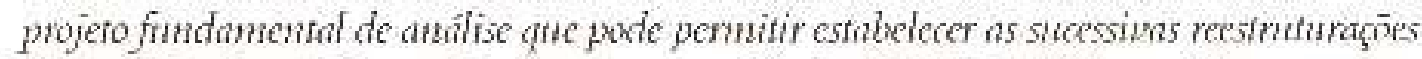

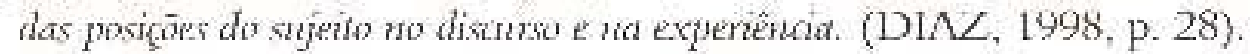

Cono é possível interir, a construça metexdologica a qui propesta uăo protmete nenhum destino ou comprecnsăo universal c totalizante acterca dos sujeitos e das relaçóes sociais e é este um dos aspectos centrais reclamados por argumentaçoes asserntadas nas petagogias críticas. Certamente, uma formulação sob inspiração perspectivista coloca-se na contramnăo das pedagoggas críticas que, como muito apropriadamente cxamina GARCIA (2002, p. 15), exereem tha conduy̆ôn dos processos de conhecimento escolar, entre eles o cnsino c o tazer doccnte, um tipo de pastorado yue preterde a produçăo de sujeicos esclarecidos e emancipados através de tecrologias pedagónicas críticas que tem na subjetivaţāo dos saberes escolares e no diatogo sens instrunentos privilegindos.

Contrariamente a essa incrustaçăo, na perspectiva aqui esboçada, os professores náo sảo vistos como portadores de algum tipo dc 


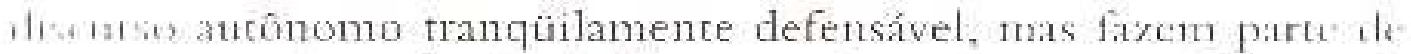
inu nstema de produçán de discursos; situam-se nos problentas de

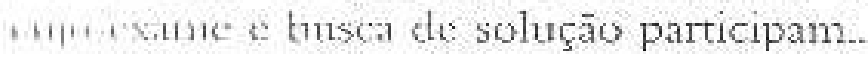

O disurso do profeswor näs ronstitui un projeto deliberado de uni falante autônomo a partir de una intençāo conumicatina, mas é assiunido a partir de una orcleni, a partir de un sistena Ae probiscäo do discurse, a partir de principios de controle e.

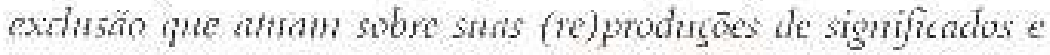
sobre stas práticas especificas. (DIAZ, 1998, p. 15).

lisse reconticcimento poderia lovar a supor o enredamento dos sujeitos 411 utermmávcis tcias imobilistas que nâo deixariarn espaço a qualquer 1 How de așin que pudesse fayer frente aos dilemas sociais c culturais ipat itravessam a agato colucativa? Ora, sc cstamos mestindo contra as ficmsoes racionalistas e umificadas, estatuos opterando $60 \mathrm{~m}$ um

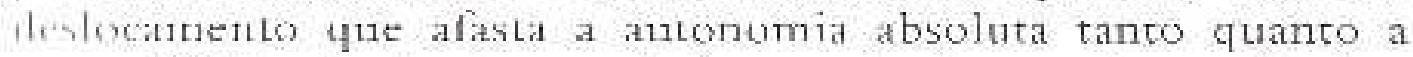
akx retbilictade de estruturas c rclaçócs apontando para a incompletude e

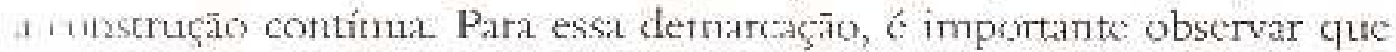

Ní̄o estanos anunciando o sujeio absolnantente subjefinalo

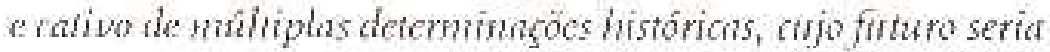
previsivel, inepitavel, cono una condenatăo. Qnando abuicamos da firgāo quixoresca do poderoso sujeito da ronstiencia e da monalidade, estanos nos cfasianto de una invengao historicaneute situada, denominada sujerto uansendenal, para admitir a possibilidade de un sujeito

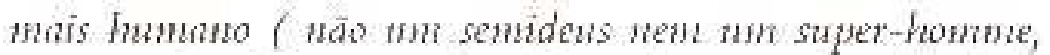
com mustas faces, maitas fronteiras, fnstios limites, descentrado, en permanmule reconstrugño em uma incessante fremenêtica de si mesno. (COS $1 \mathrm{~h}, 2000$, p. 44).

Ent decotrência desse raciocínis, a ação formativa do doccnte formador deve ser recolocada no interior de uma dinâmica que, desta vez, trăo na perspectiva de tuutua postura modelar, o indui como sujcito qute $<$ tambén formado, constituído, regulado no discurso pedagógico; que interage de modo narrativo e discursivo conn suas proprias comdiçōes de existência tanto guanto com as opcraçócs formativas dos estudantes. 


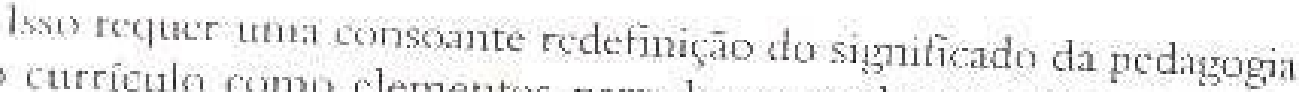
c che curríula como clementos narrados e produtores de narrativas, 11in portadores de alquin tipo de verclade transcendetital ou antônoma que disponibiliza algum esjaç politicamente purificado, mas intersticios pontuados sempre por produtivas reliçoes de posder.

Poderia nesse aspecto ser bastante fértil uma noçāo de pedagogia entendida

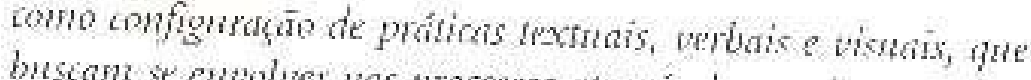
bustan se entolver was procesios atratés his quais as pessoas se enfenden, ens manciras em que se enpoluen wom ar ontras persors e con sen andriente. [...] Cono forna de produgroio cultural, a pedrigogia está implicada na constracio e oygarjizruäo de conhurinientos, desejos, valores e práticas sociais. (CIROUX, 1909, p. 14).

Assim, encontra-se ativanefitc envolvida em relaçóes de poifer

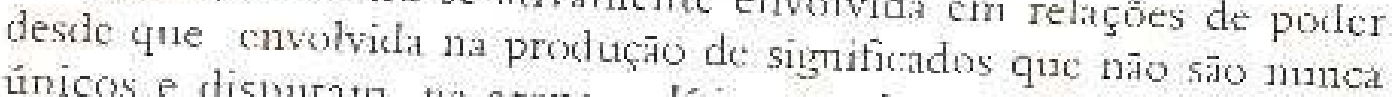
únicoss e disputann, fla arena política c cultural, sua legitimạ̄a o afirmaç̄o.

Articuladanente a essa redefiniçāo da peday̧ogia calsc primar por uma compreensāos do currículu que, ainda na jerspectiva de GIROU JX

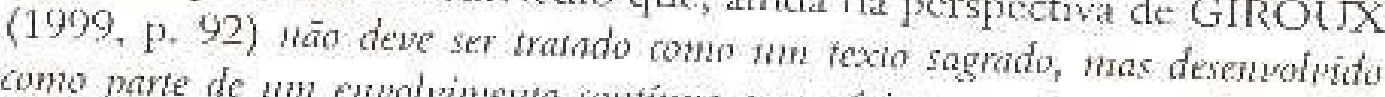
como parte de un envolnimento contíno con várias narrativas e tradişöes que poden ser relidas e transformadas em ternos politicanente diferenses.

Isso aponta a neccssidade de diversificaçấo dos materiais curriculares apropriados para o encontro com diferentes formas narrativas, orais, literárias, midtáticas, cscritas, semióticas, iconogrâficas, documetitais fá produzidas on a screm produzidas, tomados como textos portadores de significados c produzidos em detcrminadas circunstâncias. Prata-sc de tumálos nắo no sentido ilustrativo das difcrentes formas de dominaçâo, mas como produçōes conlingentes, que possibilitam a geraçāo de contranarrativas que, guestionando narrativas, as clesconstruan ern seu carâter afirmativo e legitimador de assimetrias fundadas em difcrenças ligadas, como excmplo, ao gु̂neto, à classe, à raça, à sexualidade, à geração, cntre outros,

No vislumbrar do que se vem denomirando como uma corrente de interpretaçāo efivolvida na construçăo de uma comunidade de pessoas inquisitivas, Professores e alunor engajan-se num diálogo com os sextos, tratando- 


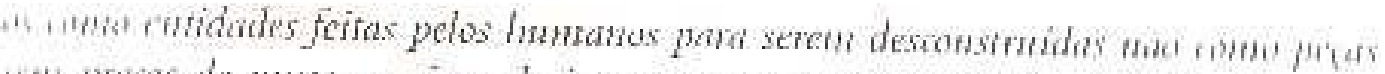

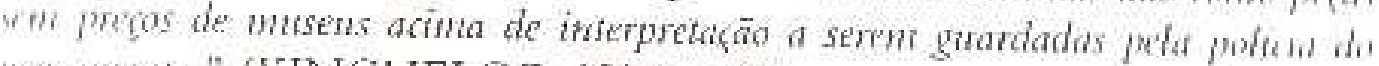
j"owncho," (KINCHILLOE, 1997, p. 89).

Pira isso, cabe ampliar a noģ̄o de materais pedağógicos curcullates 11.uta alór dos cirnones da literatura pedagógica estritamente consideradi. iterausifuando-os, desfotichizando-os c assirn atentando para as marcas ale

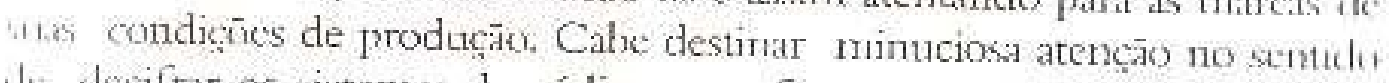
1. deciftat os sistemas de cóligos que faxem com que esses diferentes

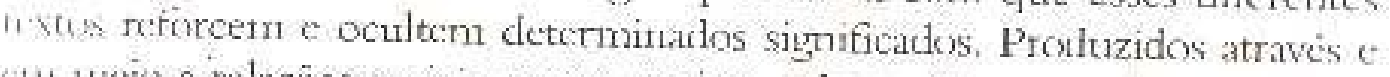
(111 uncio a relaçöes sociais, textos escritos, relatos, filmes, on doors, cançexs, hingrafias, arturus, cartas, crônicas hutnorísticas, conto diferentes aparatos iliveursivos en mcio ass quajs os estudantis e protessors circulam ros. liferentes âmbitos en que travam suax Jutas cotidianas, expressamn e 1 urtestam significados de projetos dommantes co subjugndos.

Diante dessc variado lequc de artefatos que institnom sujcitos o prodizem verdades, as operaçoses metodolígicas necessárias para o tratsalho tormativo, nessa perspcciva, deixam de ser tum leque de tienicas ou procediuncntos elcitos com fins de liversificaçăo de aços para terem sua escolha contingenciada pela perspectiva teorica deita para o trabaltuo natrativo e pelas possibilidades aprescntadas para a desconscrucāo e reconstruçăo das visōes, discursos c príticas que constroem as subjetividados e o espaco socio cultural que as atravessam.

Para tanto vale a proituçấo de metodos erítıcos pós-modernos consubstaticiados im projetos sonealógicos, escritas autubiograficas, unstrucoses textuais, entrevistas clínicas. procedimentos reflexivos, málise toxtual construtiva, práticas de diario e mctodos colaborativos de avaliaçāo c interpretaşăo dessis atividades. (KINCHELOE, 1997).

Na perspectiva aqui delendida, a utilizaçăo de qualuner urm desses procedimcnus requer uma açăo voltada năo somente para co conjurato de equpamentes c mecanismos que atravessarm as construcócs narrativas, mas pata uma comprecnsio dos sujeitos almos e profestores como corpos, mentes c seres de linguagem - supcrficies de irjscriçăo - que nāo ajenas retratar ou reflecem esses disposilivos, tras os trazem como textos itescritos no que falatm, no que vestem, no que si: scnsibilizam, no que negrnt, nas diferentcs ${ }^{+}$ou indificrentes" posiçōes - do - sujcito que constroeth.

Parat alêtr de uma leitura cxógena, é necessátio que cducadores c cstudantes se lciarn conso texos vivos, wan suns historins de vida, suas estórias, setus

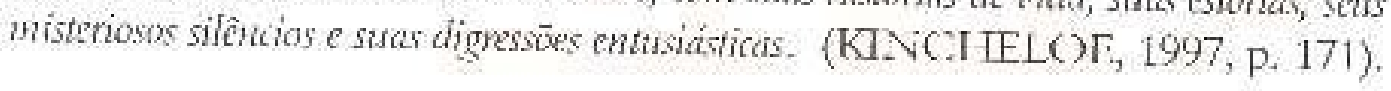


Submeter e expor a expcriçncin à tcorizaçăo passi a ser unt esforço no qual estudantes e professores devem envolver-sc. Isto nāo st: reduz a cncontrar os lianes teóricos dos raciocínios, on legitimá-los e justificálos a partir de algutra formulaçao tcórica; mas, fundamentalmatste, comprecndé-los nor contextes das estruturas e relaçóes que os produzcm de detcrminados modos, esquadrinhandw sempre ent que medida reforçatr ou contestam relaçóes de poder. Signitica perscrntar as concxoes entre as experiências \& narralivas individuais e colctivas, de ınodo a rcconstrui-las como experiencias de si mestruo e experiências do outro encendidos nâo como individualidades narcísicas, mas como seres siltural, linģística e socialmente enredados. Significa fazer da açâ curricular cotidiana uma açăs assumiclamente investigativa. Uma açüo petquiridora do objetos que näo cxistem independentemente de stuetr os Furrulat de quen os narra, de quem os cnuncia.

Dessc modo, os contenidos de crnsint the experiência formativa transvetsalizatn-se para alèm de campos disciplinares c passam a ser produzidos, idetulificados e expostos à crítica no processo do mecração entre professorcs c alunos atravessado por uma variedide de elementos tuxtuais, cultırais e experieticiais trabalhados $\mathrm{cm}$ situaçoes de cnsino que propicion o cxame das concliçōes en sule verdades e realidades sāo estabelecidas. Dispensam assim qualquer perspectiva ntilitarista,

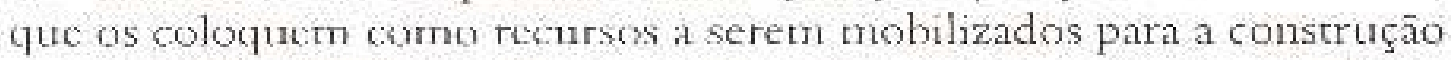
de competências definidas como ideal formativo c passatn a trabitar 11т катpo de decisóes curriculares contraposto tanto a uma epistcmologia fatalística gulanto a pé́licas espontaneístas ou desígnios messiânicos. Nessa dimensāo, a cxigência tórírica é práticia fiundamental. Nơ marujos foucaultianss, a teosria nâo expressa, traduz ou aplica una prática, cla é uma práticat; é local, tuāo totalǐadóna; uma caixa de ferramentas; que se multiplica c multiplica.(FOUCAULT, 1996).

Os conteúdos curriculares nâo sầo somcnte aqueles çu diæ:m respeto aos saberes arregrimentados e sancionados na sociedade mas provocam a insurreiçño daqueles saberes loçìs, singulates, "Slesqualificados".

A rclação proféssor - alumo passa a ser uma relação de sujeitos que se reconbecem também como cfcitos dc implicneoges fundantentais de podersaber e de snas transformaşos históricas. (FOUCAUL1, 1989, p. 30). Reconhecem os limites da autoria de suas experiências, nufn processo wrule se situam etn e no conhecimento, expostos $\mathrm{cm}$ suas fragilidades $c$ inconsistências, ch sua incompletude e ra incorrupletude das histrórias 


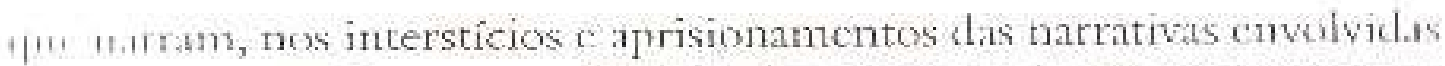

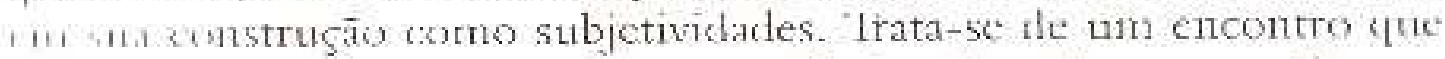

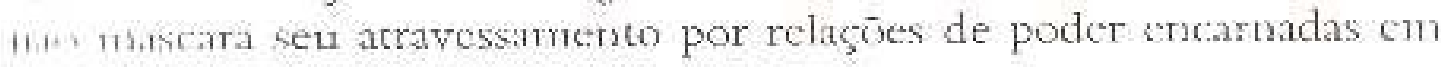
31. produtividade e năo apcnas nomo força neggativa.

lin decorrência, a prática avaliativa passa a st:r um esforço de

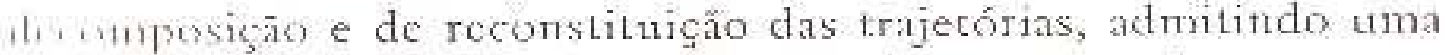
in a salude de fontes e referencias que permitem acompanhar processos mhetuvos e cognitiyos jutimamentc articulados à compreensâo da

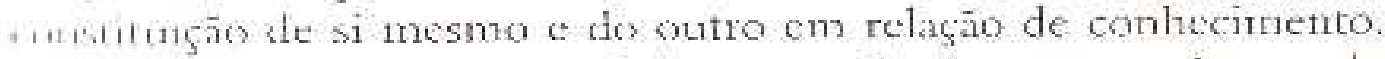

Asomt o que matram os sujeitos acerca de si tresmos c do mundo tal

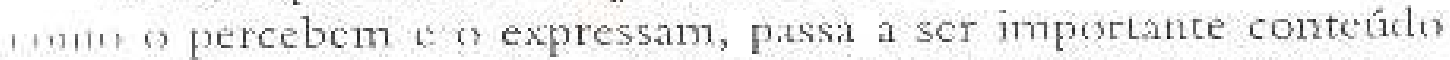

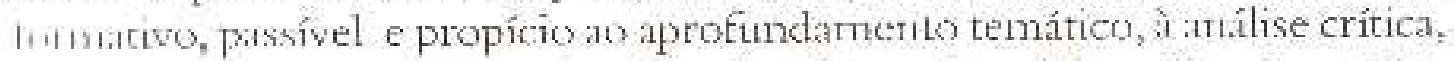

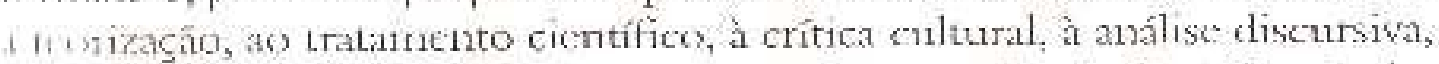

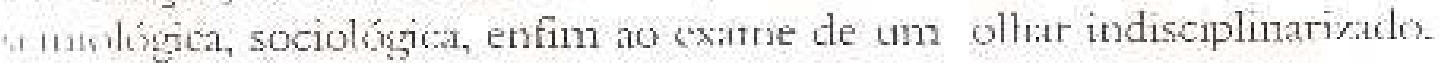

\section{Concluindo}

Rccorremolo aos clemettus aqui apresentados, e mecessário wirmar que uma perspectiva notodologica que fetr a linguagcm e a 1mixluçāo stibjeliva como porutos básicos de referência, nāo recorre às H.urrativas como uráculos retrospecfinos. As narrativas são vistas como 14 incas, oljetos de luta dune apontam o presentc, relaciouam-se com o p'assado, acionarn vircualidades futuras, e essa posiçāo requet para a clucação uma outra relórica. Do ponto de vista epistemostógico implica - m cransformaçós nas tortuas de sc conceber a ciencia e a linguagem I partir do ponto de vista de scu poder de criar sujeitos. Do ponto de vista th una reconceptualizaçás da educaçär, pode ser útil o sulendiments de unna cducaças poética gue sabe

que a palavo hanana éplural eque esia palazra, ou palauras, ten semido năo somente peto que dizen, mas fanbém $c$

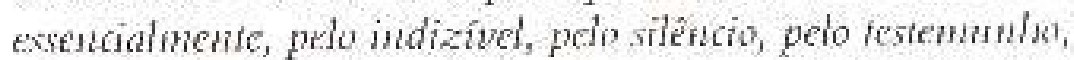
pela alseritade, pela ausenta. E nnmbém pela frogitidade $c$ a paluerabilidade, pelin mesticagen e a fronteina, pelse desaparecimento de pontos de referencia estáveis e nbsslutos." (MËLICII, 2001, p. 279).

Cabc em narrativas de nossa passayzen no mundo, os que somos rorvidados da vida.... 
15U1:NO, Belmira. O mécodo autobiográfico es ostudos com histórias ds- vida de protissores: a questão da siabjetividade. Edncagrio e Pesguisn. V. $28 . N^{\circ}$ 1. São Paulo. Jan./fun. 2002.

BUJES, Maria lsabel. E. Descatninbos, La: COSTA, Marisi Vorraber

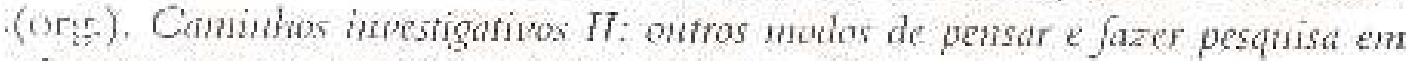
rdragsio. Rio de Janciro: DPRA Edicota, 2002; p.11-34.

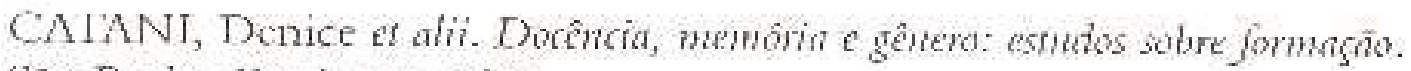
Sío Paulo: Escrituras, 1997.

CORA77.A, Sandra \& SILVA. Tomaz laden da. Connosicōes. Belo IIorizonte: Antôntica, 2003.

COSTA, Marisa Vorraber. Sujeito e subjelividade nas tramas da lingriagem e da cmltura. In: CANDNU. Vera Maria (Org.). Cuitura,

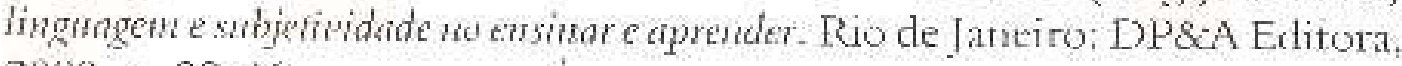
$2000 \%$, p $-29-46$.

DEMART1N1 el alii. Magistério primálux: protissầo fetrinina, carreitat masculina. Cadernos de Perquisi, n' 86, p. 5-14, Agosto.1993.

DL/ M, Mario, Foucault. docentes at discursos pedagogicos. hn:SULVA, Tormaz Tadeu da (Org.). Liberlades reguladas: a pedizogia constrativista e untras formos de governo do en. Pecrópolis: Vozes, 1998, p. 14-29.

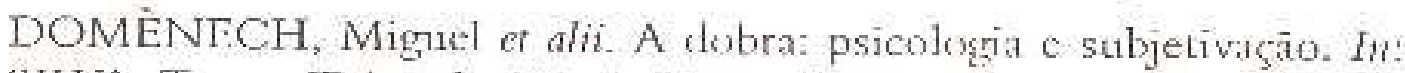
SILVA. Tomaz Tideu da (Ory.). Nuned fonos thio homanos- nos rastros do snjeilo, Belo Horizonte: Auténtica, 2001.

GLATTARI, Fix. Caosmose um novo paradignia estétio. Rkio de Janciro: Ed. 34, 1992.

NGVOA, Antotio, Vida de projessores. Portugal: Porto Ed, 1992.

NOVOA, Antonio; FINCER, Matias (orgsi) O método (autobloiografiro e a formą̧āo. Lisboa: Ministério da Saude, Departannento dos Recursos Hutranos da Saúde/Cencro de Formação c Aperfiçoamento Profissional, 1988. 


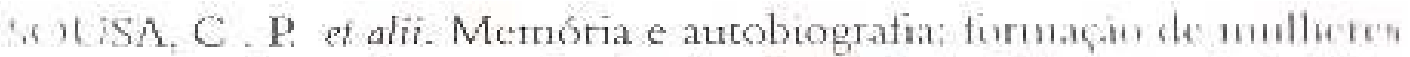

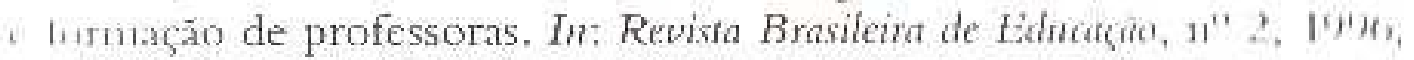
1. $\langle 1,-76$.

16 UCNULT: Miche1. A arquelogia do saber, $4^{2}$ ed. Rio de Jancate. I inesuse Universitária, 1995.

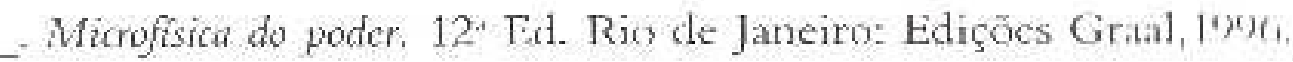
ITgiar e punir. Petrúpolis: Vozes, 1989.

A.ALT O, Sílvio. Nesas deleuzianas para nurna filosolia da educação. hy:

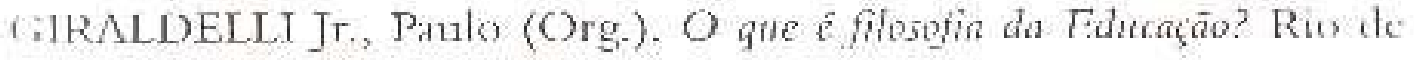
limeirs: DP\&ar Editora, 2002.

CiARCTA Maria Manucla Alves. Pedagigias orífias e subjetivagáo; wma jerspectiva foncrultiana. Pelrópolis: Vozes, 2002.

MÈLICH, Joan-Carles. A resposca ao outro: a carícia. In: LARROSA, Jurze \& LARA, Nuria Pérez de (Orys.). Inagens do sutro. Tetrópolis: Vozes, 1998.

M1GNOT, Ana Chrystina V. CUNH/, Maria Teresa Sartos (Orgs). Práliax de memórin docente. São Panlo: Cortez Editora, 2003,

KINCHELOF, Joe F. A formacño do professor cono ampronisiso politico. Porto Alegre: Artes Medicas, 1997.

MALÉS, Joscnilda. Casaco de Arlequim: composiçōes provocativas para outras ptíticas. Temitórios didáticos: sabores e yráticas. Belém: E. F. S., 2000, p. $13-34$.

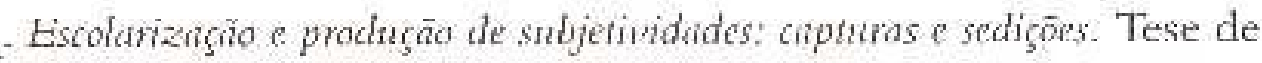
Doutoramento. PUC: São Paulo, 1998.

ROST, Nicolas. Inventando nossos cus. In: SILVA, Iomaz Tadeu da (Org.). Nunta fomos tāo humanos: nos msins do sujkito. Belo Horizontc: Autếntica: 2001, p. 138-204.

SERRES, Michel. Filosofia nestica. Rio de Janciro: Nova Fronceira, 1993. 